\title{
DEPRESSION OF THE HEART BY QUINIDINE AND ITS TREATMENT
}

\author{
BY \\ T. R. L. FINNEGAN AND J. R. TROUNCE \\ From the Departments of Pharmacology and Medicine, Guy's Hospital \\ Received April 23, 1954
}

Sudden collapse, sometimes followed by death, still occurs during the administration of quinidine, in spite of selection of cases by criteria that are now widely accepted. Post-mortem examinations show in some cases an embolism in some vital organ, but in others no obvious cause of death can be found. The object of this investigation was to throw some light on the cause of death in these patients and to suggest possible remedies.

Observations have been made on patients who collapsed while receiving quinidine and on the electrocardiogram of patients who, although receiving quinidine, showed no toxic effects from the drug: finally, a certain number of experiments were carried out on animals to supplement the observations on man.

\section{OBSERVATIONS ON MAN}

Among 115 patients treated with quinidine in the last six years at Guy's Hospital for cardiac arrhythmias there have been one fatal and two severe reactions.

Case 1. Mrs. O., aged 28, had a successful mitral valvotomy and was left with minimal aortic stenosis. Two years later she developed auricular fibrillation and after preliminary control by digoxin, which was then omitted for two days, she was given quinidine, $0.2 \mathrm{~g}$. stat. and $0.2 \mathrm{~g}$. two-hourly. After a total of $1.2 \mathrm{~g}$. she reverted to sinus rhythm and the quinidine was stopped when she had taken a total of $1.4 \mathrm{~g}$. Half an hour later she became acutely distressed with signs of congestive cardiac failure. A cardiogram at this time (Fig. 1) showed bradycardia, with a shifting pacemaker. She died suddenly a few minutes later. Necropsy revealed no cause of death.

Case 2. Mrs. P., aged 55, developed auricular fibrillation without apparent cause. This was controlled by digoxin, which was then omitted for one day. She was then given quinidine, $0.3 \mathrm{~g}$. on the first day, $0.6 \mathrm{~g}$. On the second, $1 \mathrm{~g}$. on the third and $1.3 \mathrm{~g}$. on the fourth day. Immediately following the final dose on the fourth day the patient collapsed with dyspnœic and generalized convulsions. Two hours later she again collapsed; the pulse disappeared and the heart sounds were inaudible for three minutes. She was then given $1 \mathrm{ml}$. of $1: 1000$ adrenaline by intracardiac injection and the heart began to beat. A cardiogram taken a few minutes later showed sinus rhythm with prolongation of the P-R interval $(0.22 \mathrm{sec}$.) and widening of the QRS complexes $(0.12 \mathrm{sec}$.). Her blood pressure was 80/40. Following methyl amphetamine $10 \mathrm{mg}$. intramuscularly it rose to $90 / 66$ and after a further $10 \mathrm{mg}$. of the same drug to $110 / 80$. By next morning she had recovered.

Case 3. Mrs. W., aged 25, had a successful mitral valvotomy. Following operation she was troubled by attacks of palpitation. She was admitted to Guy's Hospital a year later and was found to have auricular flutter with varying $\mathrm{A}-\mathrm{V}$ block. This was converted to auricular fibrillation by digoxin and 24 hours after. stopping this drug she was given quinidine. She received $1.6 \mathrm{~g}$. the first day and reverted to sinus rhythm. The following day, three hours after receiving a maintenance dose of $0.3 \mathrm{~g}$. of quinidine, she developed a further sudden burst of auricular fibrillation followed by a fit. She was pulseless for nearly a minute, and then the heart started again in regular rhythm. A cardiogram taken a short time later showed sinus rhythm with bradycardia. She was given ephedrine for the next five days and there were no further attacks. 


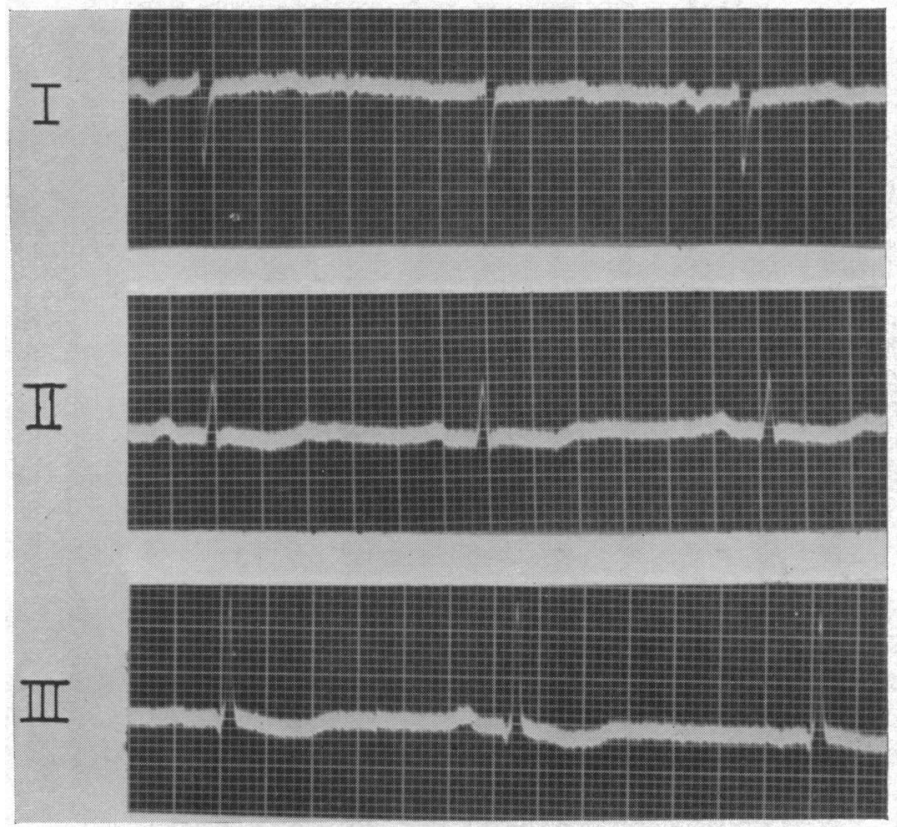

FIG. 1.-Electrocardiogram of Case 1 four minutes before death, showing a wandering pacemaker.

The first problem to be decided in these patients is the mechanism underlying their collapse. The onset is sudden and unexpected and observations are therefore scanty and imperfect. Our own cases and others that have been reported suggest that the collapse is associated with weakening or disappearance of the pulse and sometimes of the heart sounds, fall in blood pressure, changes in the electrocardiograms, and sometimes depression of respiration. The cardiographic changes can be divided into two groups. In our three patients as well as in the case reported by Wilson (1926), the main alterations consisted of depression of the bundle and nodal tissue with probable cardiac arrest. The other abnormalities that have been reported in association with severe reactions are ventricular tachycardia or fibrillation (Kerr and Bender, 1922; Schwartz and Jerez, 1934; Jerez and Schwartz, 1935; Rakov, 1942; Bender and Rosove, 1952). With both these disorders of cardiac function there would be a drop in cardiac output with the attendant fall in blood pressure, and it is suggested that in these cases the acute collapse of circulation is primarily of cardiac origin.

The depression of nodal and conducting tissue is quite compatible with the usually accepted pharmacological actions of quinidine. The development of ventricular arrhythmias, however, is very difficult to explain and is a problem awaiting further elucidation. In spite of experimental work (Kwit and Gold, 1935; and Gold, 1950) there is no clear evidence that the combination of quinidine and digitalis in normal doses predisposes to ventricular tachycardia or fibrillation. Of the seven reported patients in whom ventricular arrhythmia was associated with severe collapse, six were not digitalized and one had received no digitalis for some days.

\section{Lesser Cardiographic Changes}

In the present series of 115 cases only five further abnormalities have been noted in the electrocardiogram. These all occurred without any symptoms of collapse.

Case 4. A man, aged 43, with lone auricular fibrillation. After $1 \cdot 2 \mathrm{~g}$. of quinidine he reverted to sinus rhythm. He then had a small testicular embolism and at this time a cardiogram showed periods of sinoauricular block; within twenty-four hours this had disappeared. 
Case 5. A man, aged 40, with mitral stenosis and auricular fibrillation. Following a successful mitral valvotomy, his digoxin was omitted for one day and he was given $2 \mathrm{~g}$. of quinidine in twenty-four hours. He then reverted to sinus rhythm and a cardiogram taken at that time showed prolongation of the P-R

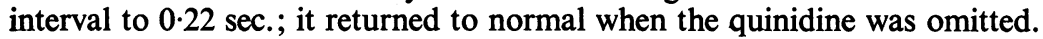

Cases 6 and 7. Both these patients, aged 31 and 34 respectively, had had successful mitral valvotomies but were left with auricular fibrillation. Their digitalis was omitted for forty-eight hours and they were then started on quinidine. After receiving $1.3 \mathrm{~g}$. over six hours they developed some widening of QRS complexes which was particularly marked during a rapid run of ventricular contractions. It disappeared when the quinidine was omitted.

Case 8. A woman, aged 33, had had a successful mitral valvotomy but was left with auricular fibrillation. Her digitalis was omitted for twenty-four hours and she was given quinidine. After $1.3 \mathrm{~g}$. on the first day she developed ventricular extrasystoles. On the second day she reverted to sinus rhythm after a further $0.75 \mathrm{~g}$. The quinidine was then stopped but an hour later she developed coupled beats due to ventricular extrasystoles. These disappeared after a further two hours.

There have been many reports of more minor electrocardiographic changes occurring after quinidine. These are summarized in Table I. It can be seen that the commonest change is depression of various parts of the heart, usually nodal or conducting tissue. These changes are similar to those seen in our own cases and are in accord with the generally accepted actions of quinidine. There are also a number of reports of ventricular extrasystoles and tachycardia

TABLE I

Electrocardiographic Changes in Non-fatal Cases

\begin{tabular}{|c|c|c|c|c|c|c|c|c|c|c|}
\hline & 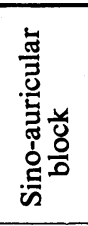 & 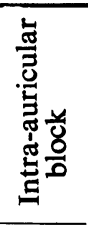 & 旁要 & 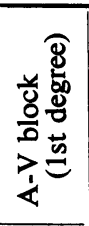 & 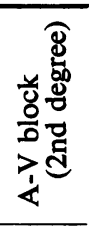 & 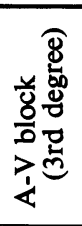 & 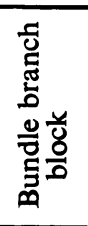 & 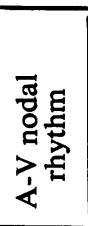 & 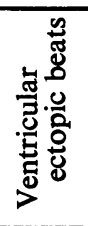 & 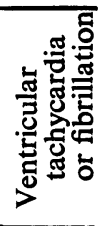 \\
\hline Hewlett and Sweeney, 1921 .. & & & & & + & + & & & & \\
\hline Clarke-Kennedy, 1922 & & & & + & + & & & & & \\
\hline Lewis et al., $1922 \quad \ldots \quad \ldots$ & & & & & & & & & + & \\
\hline Levy, $1922 \quad$.. $\quad$.. $\quad$.. & + & & & & & & & & + & + \\
\hline $\begin{array}{llll}\text { Korns, } 1923 & \ldots & \ldots & \ldots\end{array}$ & & + & & & & & + & & & \\
\hline Wolff and White, 1928 & & & + & & & & & & & \\
\hline Campbell, 1932 & & & & & + & & & & & \\
\hline Campbell and Gordon, 1936.. & & & & & & & + & & & \\
\hline $\begin{array}{llll}\text { Hall, } 1936 & . . & . & . . \\
\end{array}$ & & & & & & & & + & & \\
\hline Rosenbaum and Levine, 1939 & & & + & & & & & & & \\
\hline Barker et al., $1943 \quad$.. $\quad .$. & & & & & & & + & & & \\
\hline $\begin{array}{lll}\text { Ferrer } \text { et al., } 1948 \quad \ldots & \ldots\end{array}$ & & & & + & & & + & & & \\
\hline Armbrust and Levine, $1950 \ldots$ & & & & & & & & & & + \\
\hline Kalmansohn \& Sampson, 1950 & & & & + & & & & + & & \\
\hline Sokolow and Edgar, $1950 \quad \ldots$ & & & & & & & & & & + \\
\hline $\begin{array}{lll}\text { Warfvinge, } 1950 & \ldots & \ldots \\
\end{array}$ & & & & + & & & + & & & \\
\hline Finnegan and Trounce, 1954 & + & & & + & & & + & & + & \\
\hline
\end{tabular}


unassociated with collapse; an example of this type of change being found in Case 8. These again are similar to the more severe ventricular arrhythmias and again their underlying cause is difficult to explain, although examination of the cardiograms of certain reported cases suggests that some are in fact auricular flutter with a functional bundle branch block, rather than a true ventricular paroxysmal tachycardia.

\section{ObSERVATIONS ON ANimals}

The effects of quinidine on the heart of animals are similar to those found in man. There may be either depression of the sinu-auricular node and of the conducting mechanism sometimes leading to cardiac arrest (Lewis et al., 1921; Korns, 1923) or death may occur from ventricular fibrillation (Cohn and Levy, 1921; Korns, 1923). These findings have again been briefly investigated and the results are given below.

Methods. Mature rabbits were used throughout. Two methods of investigation were used. In the first series of experiments the isolated rabbit's heart was perfused with Ringer's solution at $28^{\circ} \mathrm{C}$. and the gross contraction of auricle and ventricle were recorded. In the second series, the rabbits were anæsthetized with ether; the electrocardiogram was recorded on a Cardioscript II, direct-writing machine, and needle electrodes were used; it was not standardized but the gain was adjusted until tracings of a suitable amplitude were produced and was then not altered until the end of the experiment. In all animal experiments a paper speed of $50 \mathrm{~mm}$. per sec. (twice normal) was used. Quinidine, as the sulphate, was given intravenously.

Results. (a) In vitro. The effects of toxic doses of quinidine on the isolated heart are well known. There is diminished contraction of both auricle and ventricle with an increasing degree of A-V block until finally contractions cease altogether.

(b) In vivo. Fig. 2 shows the effect on the cardiogram of $10 \mathrm{mg}$. per kilo of quinidine sulphate intravenously. This is the typical response to a fatal dose of quinidine. There is bradycardia with gross deformity of the QRS complexes; the P waves have disappeared; sometimes there are short

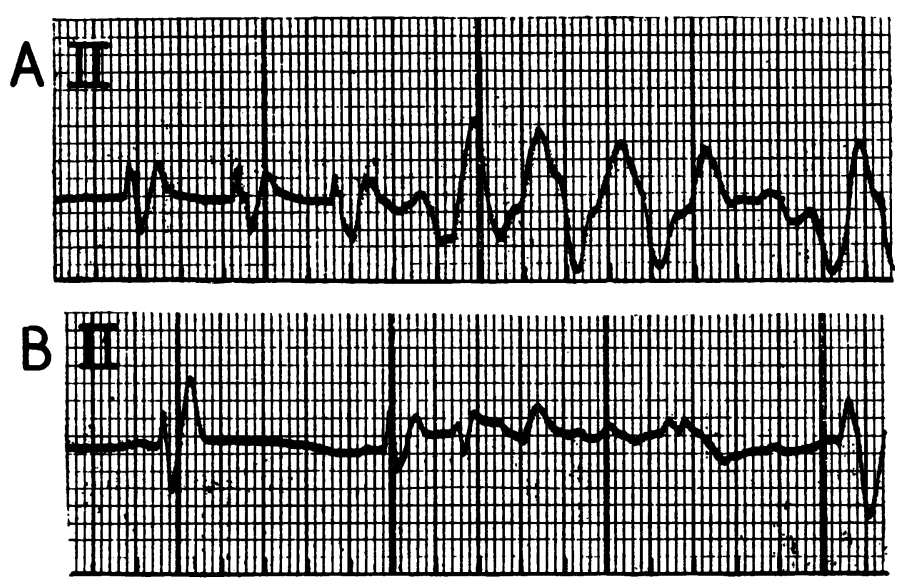

FIG. 2.-Electrocardiogram of a rabbit, lead II (paper speed $50 \mathrm{~mm}$. per sec. (A) One and a half minutes and (B) three minutes after quinidine sulphate $27 \mathrm{mg}$. intravenously.

runs of apparent ventricular fibrillation. At the same time there is usually profound depression of respiration.

If a non-fatal dose of quinidine is given, the first abnormality that appears is usually a bundle branch block. This may disappear after a few minutes or, if the dose of quinidine is sufficient, it may proceed to partial A-V block. This usually passes off in about five to thirty minutes, first the $\mathrm{A}-\mathrm{V}$ and finally the bundle branch block disappearing.

Our observations therefore confirm previous experimental findings and show that the effects of 
quinidine in animals are very similar to those found in man. There is diminution of the amplitude of cardiac contraction with depression of the nodal and conducting tissue. In animals as well as in man, ventricular fibrillation may sometimes be produced.

It may be argued that doses which were relatively very much larger than those usually used in man were required to produce these changes; however, even excluding the possible difference in sensitivity of different species, most of the toxic effects observed in man occurred in hearts that were already damaged and there is good evidence that in man at least the cardiographic changes are more common and more marked in diseased than in normal hearts (Ferrer et al., 1948).

\section{Revival of the Heart Depressed by Quinidine}

In patients who die while receiving quinidine there is often a short period of collapse before death occurs. If suitable treatment could be given in this period the patient's life might be saved. The first part of this paper suggests that the collapse is due either to cardiac depression with later arrest or to ventricular fibrillation.

Using the experimental animal, the various methods of reviving the heart depressed by quinidine are now considered. The treatment of ventricular fibrillation has not been included.

The in vitro and in vivo methods were the same as those already used in investigating the effect of quinidine on the heart.

(1) Adrenaline and Noradrenaline. An antagonism between quinidine and adrenaline has previously been noted by Mancini and Graubner (1940). In Fig. 3 and 4 the effect of adrenaline hydrochloride and noradrenaline on the isolated heart, depressed by continuous perfusion with

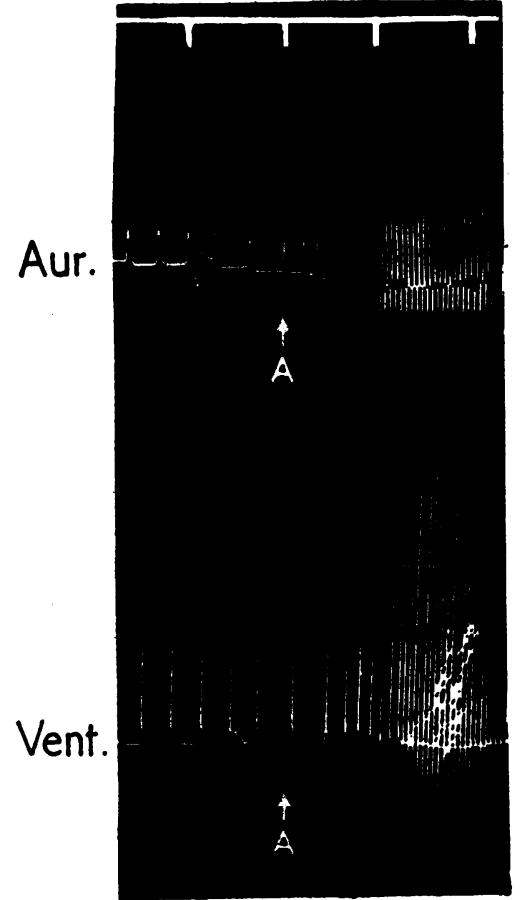

FIG. 3.-Record of the contraction of the auricle and ventricle of the isolated rabbit heart (drum speed 0.296 mm. per sec.) perfused with Ringer and 1 in 10,000 quinidine sulphate. (A) represents the addition of $0.2 \mathrm{mg}$. of adrenaline.
Aur.
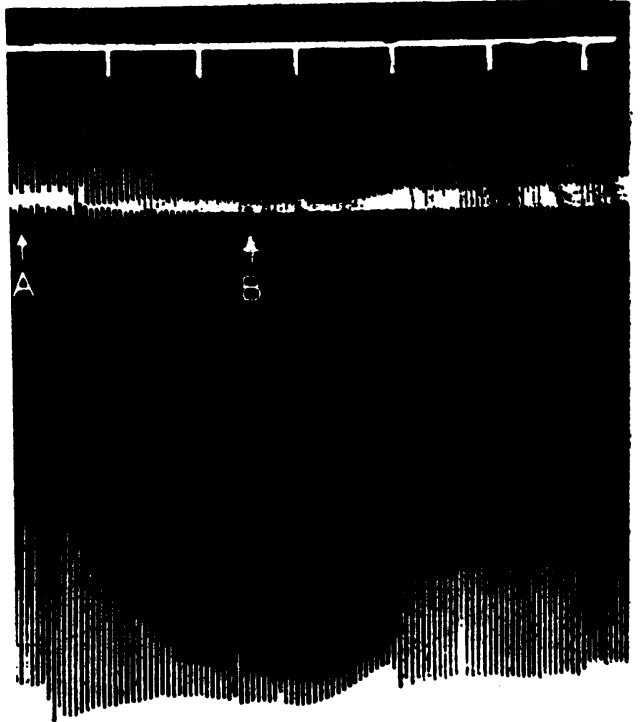

Vent.

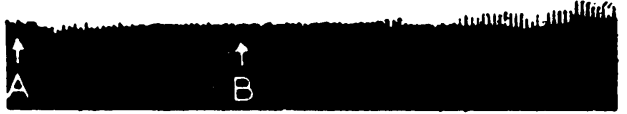

FIG. 4.-Record of the contraction of the rabbit's auricle and ventricle perfused with Ringer (drum speed $0.296 \mathrm{~mm}$. per sec.). (A) represents the start of perfusion with 1 in 10,000 quinidine and (B) the addition of $0.2 \mathrm{mg}$. of noradrenaline. 
$1: 10,000$ quinidine, is shown. It can be seen with both drugs that there is restoration of rate and amplitude of contraction of both auricle and ventricle.

In the intact animal, however, it is by no means so easy to decide whether a drug modified the depressing effect of quinidine on the heart, as the effect of quinidine itself is so variable both in severity and duration. It was found, however, that following a suitable dose of quinidine, adrenaline intravenously would temporarily reverse the toxic action of the quinidine. When the relatively short-lived action of the adrenaline passed off, the toxic effect of the quinidine reappeared and could again be modified by a further dose of adrenaline. This is illustrated in Fig. 5 where the partial recovery with adrenaline followed by relapse and then recovery again is well shown.
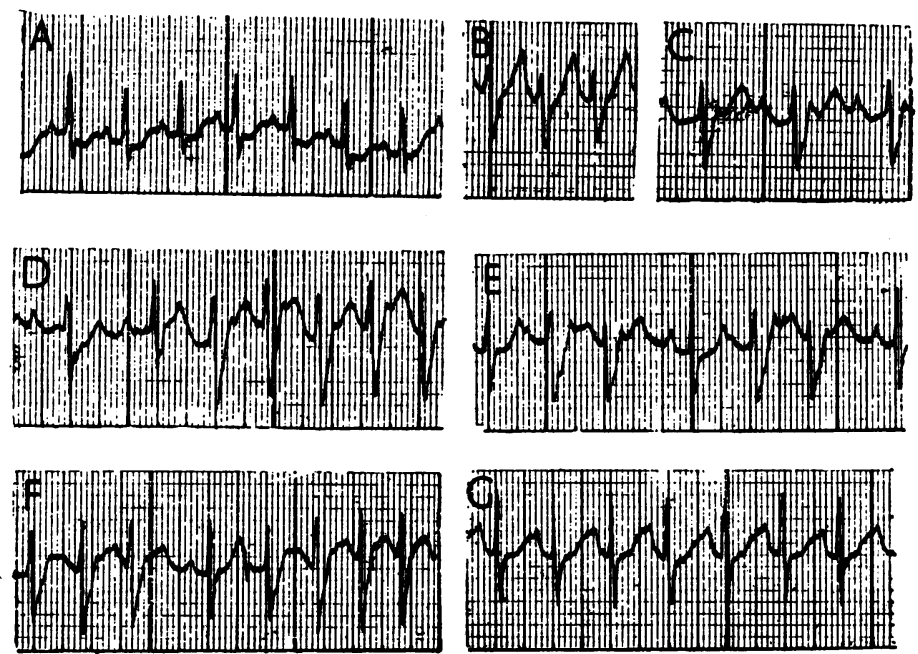

FIG. 5.-Electrocardiogram of a rabbit, lead II (paper speed $50 \mathrm{~mm}$. per sec.). (A) Before any drug has been given. (B) Two minutes after $25 \mathrm{mg}$. of quinidine sulphate intravenously, showing development of bundle branch block (C) Six minutes after quinidine showing $2: 1 \mathrm{~A}-\mathrm{V}$ block. (D) Eight minutes after quinidine, half a minute after adrenaline $0.1 \mathrm{mg}$. intravenoulsy. The A-V block disappears, but the bundle branch block becomes more pronounced, probably owing to the greater rate of ventricular stimulation. (E) Eleven minutes after quinidine, three minutes after adrenalinc. Heart relapses to an alternating $2: 1$ and $1: 1$ ventricular response. (F) Fifteen minutes after quinidine, half a minute after a further $0.1 \mathrm{mg}$. of adrenaline intravenously. The heart returns to a $1: 1$ ventricular response. (G) Thirty minutes of quinidine, one minute after a further $0.05 \mathrm{mg}$. of adrenaline intravenously. The bundle branch block finally disappears.

A similar result was obtained on one occasion with noradrenaline. These effects could not always be produced and a summary of the results is given in Table II. The results suggest that noradrenaline is less powerful than adrenaline but are too few in number to come to any definite conclusion. The more powerful action of adrenaline on the heart would be in keeping with the previous report of West (1947). It was also found that the restorative action of adrenaline and noradrenaline was limited to those hearts showing bradycardia with varying forms of A-V block; it was never possible to restore the heart if complete arrest had occurred.

(2) Phenylephrine. Phenylephrine has been reported as antagonizing the action of quinidine (Mancini and Grauber, 1940). It was not possible to show any effect either in vivo or in vitro on the rabbit heart depressed by quinidine.

(3) Caffeine. Caffeine was suggested long ago as an antidote for the toxic effects of quinidine. 
TABLE II

Response to Adrenaline and Noradrenaline of the Heart in the INTACt ANimal Depressed by QUINIDINE

\begin{tabular}{cc|c|c}
\hline $\begin{array}{c}\text { Type of } \\
\text { response }\end{array}$ & $\begin{array}{c}\text { To } \\
\text { adrenaline }\end{array}$ & $\begin{array}{c}\text { To } \\
\text { noradrenaline }\end{array}$ \\
\hline Stimulation* &.. & 3 & 1 \\
\hline $\begin{array}{c}\text { Possible } \\
\text { stimulation } \dagger\end{array}$ & $\ldots$ & 2 & 5 \\
\hline No effect $\ddagger$ & $\ldots$ & 4 & 3 \\
\hline
\end{tabular}

* Stimulation=Recovery with stimulating drug within two minutes, followed by relapse and further recovery with a second dose of the drug.

$\dagger$ Possible stimulation=Recovery with stimulating drug within two minutes, but no further relapse. In this group it is impossible to exclude spontaneous recovery.

$\ddagger$ No effect $=$ No change in the electrocardiogram within two minutes of giving the stimulating drug.

Gordon et al. (1925) reported that in cats caffeine was effective in relieving cardiac depression, provided artificial respiration was used to deal with the concomitant respiratory depression.

In the isolated perfused heart caffeine appeared on one occasion to have some slight restorative effect. The result, however, could not be repeated. In vivo it was not possible to show any stimulating effect on the heart depressed by quinidine. Caffeine was certainly not as effective as adrenaline.

(4) Ephedrine. Ephedrine should theoretically have some reviving effect on the heart depressed by quinidine. The effect on the isolated perfused rabbit heart depressed by quinidine was variable; sometimes there was no appreciable effect, at others, slight further depression. It is well known that cardiac depression with ephedrine can occur (Chen and Schmidt, 1930) and that the cardiac stimulating effect is less than that of adrenaline (Starr et al., 1937).

Ephedrine did not seem, therefore, to be such a suitable drug as adrenaline for reviving the heart depressed by quinidine and this was in fact confirmed by its failure to have any action in vivo.

(5) Acetyl choline. Briscoe and Burn (1954) reported that if the contractions of the isolated rabbit auricle were arrested by quinidine, the addition of acetyl choline would cause a resumption of spontaneous activity. The concentration of acetyl choline required varied widely; the mean concentration in nine experiments was $1 \cdot 2 \times 10^{-5} \mathrm{~g} . / \mathrm{ml}$. Further, if the rate and amplitude of contraction were diminished by quinidine the addition of acetyl choline would be followed by a brief slowing and then an increase in both amplitude and rate of contraction. A further addition of acetyl choline was followed by inhibition and arrest of contraction.

Acetyl choline was, therefore, investigated by us to see whether it might be useful clinically in reviving the heart depressed by quinidine. In the isolated perfused heart the results are rather variable. They are summarized in Table III. It can be seen that the addition of $10.0 \mu \mathrm{g}$. and $1.0 \mu \mathrm{g}$. of acetyl choline will sometimes produce a transient stimulation of the depressed heart, particularly of the auricular muscle; such a response is shown in Fig. 6. In no experiment in which the heart responded to acetyl choline did the subsequent addition of adrenaline produce a smaller response than that due to acetyl choline and usually it was much greater: neither was it possible to revive a heart with acetyl choline when it had failed to respond to adrenaline.

In the intact animal, the actions of acetyl choline again suggest it may not be suitable for reviving the heart depressed by quinidine. Fig. 7 shows the cardiogram of a rabbit half a minute after receiving $1.0 \mathrm{mg}$. of acetyl choline intravenously. It can be seen that there is slowing of the auricular rate with partial A-V block and, at the same time, increased excitability of the auricle with short runs of auricular fibrillation. Acetyl choline $0.5 \mathrm{mg}$. intravenously produced cardiac slowing with occasional auricular extra systoles and 0.1 and $0.01 \mathrm{mg}$. intravenously produced only cardiac slowing. It can be seen therefore that in the rabbit although acetyl choline appears to increase the excitability of the auricular muscle, it depresses the S-A 


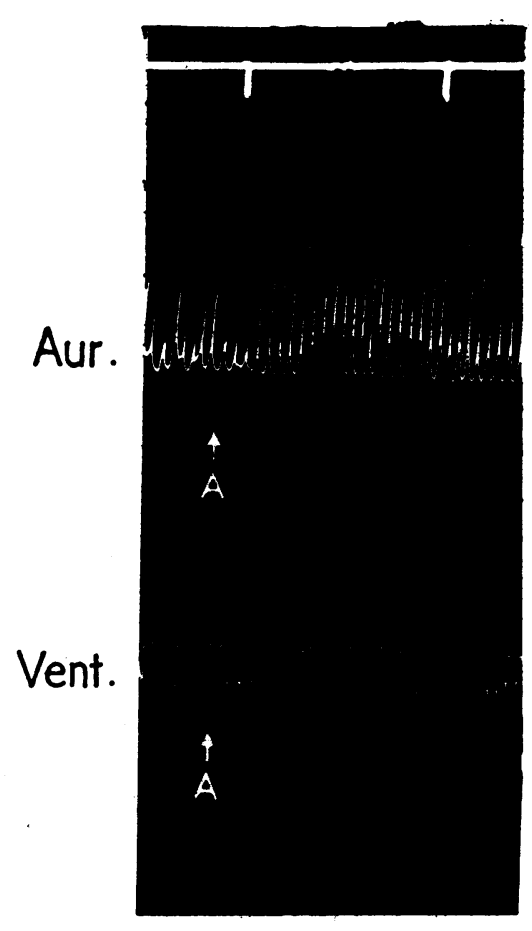

Fig. 6.-Record of the contraction of the isolated rabbit heart continuously perfused by Ringer and $1: 10,000$ quinidine (drum speed $0.583 \mathrm{~mm}$. per sec.). (A) represents the addition of $10 \mu \mathrm{g}$. of acetyl choline to the perfusing fluid. node and sometimes the bundle of His, over a wide range of dosage, though this particular action might be in part blocked by the quinidine (Starr, 1936). In dogs and man acetyl choline may also produce cardiac arrest (Ajmone-Marsan and Fuortes, 1949; Phillips, et al., 1952). It would not be unreasonable to suppose that in the heart already depressed by quinidine, where the main effect is on the bundle and nodal tissue, the addition of acetyl choline would certainly not stimulate and might well further depress these important structures.

When acetyl choline was in fact given to the intact animal with severe cardiac depression from quinidine, it had no apparent effect as recorded on the cardiogram. When the depression was not so severe there was some further slowing of the heart but usually no other change. One one occasions, however, the cardiac slowing was associated with decrease in the degree of the bundle branch block. This may well have been due to the lower rate of stimulation of the ventricle rather than to any direct action of acetyl choline on the bundle of His.

The other main difficulty in using acetyl choline to revive a heart depressed by quinidine is that both our observations and those of Briscoe and Burn (1954) suggest that the dose is critical and overdosage may well stop the heart if this has not already occurred. There are so many factors that effect the concentration of the drug reaching the heart that even in the experimental animal the exact concentration of the drug achieved is very difficult to determine. This becomes an even more difficult problem when its clinical application is considered.

In conclusion it may be said that among the substances studied in the experimental animal, there is no doubt that adrenaline and noradrenaline are the most powerful and consistent drugs for reviving the heart depressed by quinidine. Caffeine has a milder action and there appears to be no serious objection to its use. With acetyl choline the response is unpredictable and the difficulties of its practical application would preclude its use at present. The actions of ephedrine and phenylephrine appear to be too weak and variable to be of much use.

TABLE III

Action of Acetyl Choline on the Isolated Rabbit's Heart Depressed by Constant Perfusion with QUINIDINE 1: 10,000

\begin{tabular}{c|c|c}
\hline $\begin{array}{c}\text { Dose of acetyl choline } \\
\text { added to perfusing fluid }\end{array}$ & $\begin{array}{c}\text { Number of } \\
\text { experiments }\end{array}$ & $\begin{array}{c}\text { Number showing } \\
\text { stimulation }\end{array}$ \\
\hline $0.1 \mu \mathrm{g}$. & 1 & 0 \\
\hline $1.0 \mu \mathrm{g}$. & 4 & 2 \\
\hline $10 \mu \mathrm{g}$. & 6 & 3 \\
\hline $100 \mu \mathrm{g}$. & 2 & 0 \\
\hline
\end{tabular}

In every experiment the subsequent addition of adrenaline $0.1 \mathrm{mg}$. would produce a similar or greater increase in amplitude of contraction. 

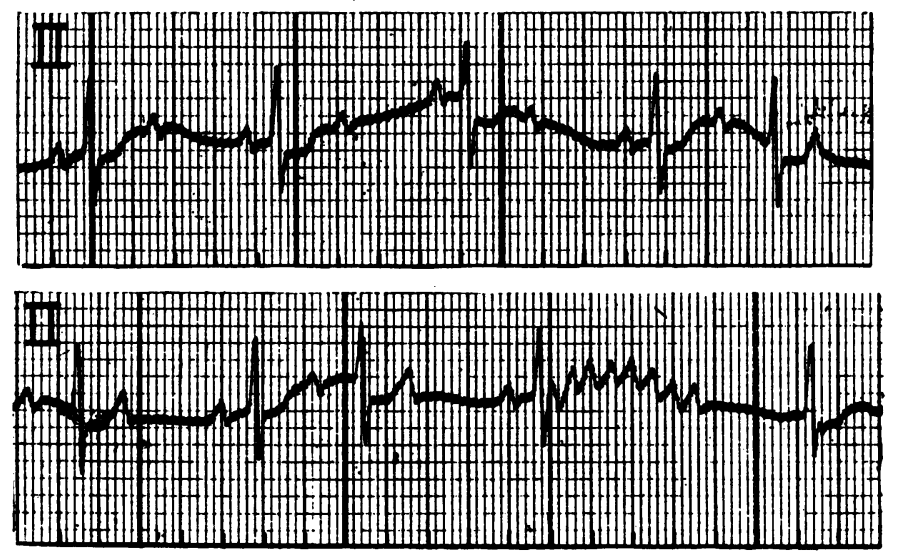

Fig. 7.-Electrocardiogram of a rabbit (paper speed $50 \mathrm{~mm}$. per sec.). Half a minute after receiving $1 \mathrm{mg}$. of acetyl choline intravenously showing bradycardia, $2: 1$ heart block, and a short run of auricular fibrillation.

\section{Revival of the Heart in MaN}

From the foregoing experimental work there would appear to be good reason to believe that adrenaline would be useful in the clinical field, in restoring the heart depressed by quinidine. Adrenaline is at present to be preferred to noradrenaline because there is more definite experimental evidence of its effectiveness in vivo and because it has been used on one occasion with success, whereas there is, as yet, no report of noradrenaline being used in such a case. It might well have a use, however, in the concomitant fall in blood pressure if this was prolonged after the restoration of the heart beat, although in our case methyl amphetamine proved satisfactory and its administration is easier to control.

It has recently been suggested that adrenaline should not be used in cardiac arrest owing to the risk of producing ventricular fibrillation (Ehrenhaft et al., 1951; McMillan et al., 1952). A completely different view was taken by Bjork (1953) who found that adrenaline restored the heart in four cases of cardiac arrest occurring in various forms of thoracic operation and, moreover, he gave up to $10 \mathrm{ml}$. of $1: 1000$ adrenaline into the heart. These conflicting results may be due to the fact that whereas in Ehrenhaft's and McMillan's cases the cardiac arrest was in no way connected with quinidine or quinidine-like drugs, three out of four of Bjork's cases had received various local anæsthetics. It might well be that the cardiac arrest in these cases was connected with these drugs, some of which have similar cardiac actions to those of quinidine (Dawes, 1946, personal observation).

The foregoing clinical and experimental work suggests that in the absence of evidence of embolism, the most usual cause of collapse is either cardiac depression and arrest, or ventricular fibrillation. It is necessary from the therapeutic point of view to decide which of these cardiac abnormalities is present as the injection of adrenaline into a patient with ventricular fibrillation might well encourage rather than relieve the abnormality. It is, therefore, important that, whereever possible, any patient receiving quinidine should be under frequent observation with the electrocardiogram.

It is generally agreed that cardiac massage is the most important part of the treatment of cardiac arrest from any cause. Unfortunately, cardiac standstill following quinidine usually occurs in the medical wards where such measures may not be practical. Intracardiac adrenaline appears, therefore, to be the only possible treatment in most of these cases and on experimental and extremely limited clinical grounds would appear worthy of trial. 


\section{SUMmaRY AND CONCLUSIONS}

The main effect of quinidine on the heart is either depression, sometimes with complete arrest, or ventricular fibrillation.

Three cases of collapse, one fatal, are reported following the administration of quinidine. The available evidence suggests that in the absence of embolism such collapse is associated with changes in the electrocardiogram, fall in blood pressure, and sometimes depression of respiration.

More minor changes of a similar but less severe nature may be found in the cardiograms of patients undergoing treatment with quinidine.

Changes similar to those found in man can be produced by giving quinidine to the experimental animal (rabbit). The heart which has been depressed by quinidine can be revived most easily by adrenaline. This can be shown in both the isolated perfused heart and in the intact animal.

The treatment of cardiac arrest in man following quinidine is discussed.

We would like to thank Dr. Charles Baker and Dr. Maurice Campbell for permission to study patients under their care and Professor Robson for his advice and encouragement. We would also like to acknowledge a grant from the Endowment Fund, Guy's Hospital, for the purchase of an electrocardiograph.

\section{REFERENCES}

Ajmone-Marsan, C., and Fuortes, M. G. F. (1949). Electroenceph. clin. Neurophysiol., 1283.

Armbrust, C. A., and Levine, S. A. (1950). Circulation, 1, 28.

Barker, P. S., Johnston, F. D., and Wilson, F. N. (1943). Amer. Heart J., 25, 760.

Bender, M. J., and Rosove, L. (1952). Amer. J. Med., 12, 491.

Bjork, V. O. (1952). J. thorac. Surg., 24, 611.

Briscoe, S., and Burn, J. H. (1954). Brit. J. Pharmacol., 9, 42.

Campbell, M. (1932). Lancet, 2, 1157.

-, and Gordon, F. W. (1936). Quart. J. Med., 5, 205.

Chen, K. K., and Schmidt, C. F. (1930). Medicine, Baltimore, 9, 1.

Clarke-Kennedy, A. E. (1922). Quart. J. Med., 16, 204.

Cohn, A. F., and Levy, R. L. (1921). Proc. Soc. exp. Biol., N.Y., 18, 283.

- (1922). Proc. Soc. exp. Biol., N.Y., 19, 174.

Dawes, G. S. (1946). Brit. J. Pharmacol., 1, 90.

Ehrenhaft, J. L., Eastwood, D. W., and Morris, L. E. (1951). J. thorac. Surg., $22,592$.

Ferrer, M. I., Harvey, R. M., Werko, L., Dresdale, D. A., Cournand, A., and Richards, D. W. (1948). Amer. Heart $J ., 36,816$.

Gold, H. (1950). Quinidine in Disorders of the Heart. Paul B. Hoeber, New York.

Gordon, B., Matton, M., and Levine, S. A. (1925). J. clin. Invest., 1, 497.

Hall, D. (1936). Brit. med. J., 2, 589.

Hewlett, A. W., and Sweeney, J. P. (1921). J. Amer. med. Ass., 77, 1793.

Jerez, A., and Schwartz, S. P. (1935). Amer. Heart J., 10, 124.

Kalmansohn, R. W., and Sampson, J. J. (1950). Circulation, 1, 569.

Kerr, W. J., and Bender, W. L. (1922), Heart, 9, 26.

Korns, H. M. (1923). Arch. intern. Med., 31, 15.

Kwit, N. T., and Gold, H. (1934). J. Pharmacol., 50, 180.

Lewis, T., Drury, A. N., Wedd, A. M., and Hieson, C. C. (1921). Heart, 9, 55.

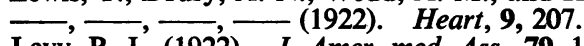

Levy, R. L. (1922). J. Amer. med. Ass., 79, 1108. (1922). Arch. intern. Med., 30, 451.

McMillan, I. K. R., Cockett, F. B., and Styles, P (1952). Thorax, 7, 205.

Mancini, M. A., and Graubner, W. (1940). Boll Soc. Ital. Biol. sper., 15, 389.

Phillips, R. M., Barlow, E. D., Storey, D. I., and Hutchinson, J. J. (1952). Electroenceph. clin. Neurophysiol., 4, 372 .

Rakov, H. C. (1942). Ann. intern. Med., 16, 571.

Rosenbaum, F. F., and Levine, S. A. (1939). Amer. J. med. Sci., 198, 774.

Schwartz, S. P., and Jerez, A. (1931). Amer. Heart J., 9, 792.

Sokolow, M., and Edgar, A. L. (1950). Circulation, 1, 576.

Starr, I. (1936). J. Pharmacol., 55, 77.

, Gamble, C. J., Margolies, A., Donal, J. S., Joseph, N., and Eagle, E. (1937). J. clin. Invest., $16,799$.

Warfvinge, L. E. (1950). Acta padiatr., 39, 262.

West, G. B. (1947). J. Physiol., 106, 418.

White, P. D., and Wolff, L. (1929). Arch. intern. Med., 43, 653.

Wilson, F. N., and Wishart, S. W. (1926). Trans. Ass. Amer. Phys., 41, 55.

Wolff, L., and White, P. D. (1928). Heart, 14, 295. 